\title{
Conversão pentecostal de membros de gangues: Construção de masculinidades não violentas em contextos pentecostais*
}

\author{
Conversión pentecostal de pandilleros: Construcción \\ de masculinidades no violentas \\ en contextos pentecostales ${ }^{* *}$
}

\section{Pentecostal conversion of gang members: Construction of non-violent masculinities in Pentecostal contexts}

\begin{abstract}
Resumo: em contextos masculinos extremamente violentos, como as gangues juvenis guatemaltecos, as comunidades de base pentecostais oferecem aos jovens membros de gangues alternativas interessantes para sair da violência. Refletir biblicamente e teologicamente sobre o impacto dessas alternativas pode ajudar a igreja a enfrentar os desafios pastorais de construir masculinidades alternativas em contextos de violência.

Palavras-chave: masculinidades não violentas, masculinidade hegemônica, comunidades pentecostais de base, gangues juvenis guatemaltecas.
\end{abstract}

Resumen: en contextos masculinos sumamente violentos, como el de las pandillas juveniles guatemaltecas, las comunidades pentecostales de base ofrecen a jóvenes pandilleros alternativas interesantes para salir de la violencia. Reflexionar bíblica y teológicamente sobre el impacto de esas alternativas puede ayudar a la iglesia a enfrentar los desafíos pastorales que implica construir masculinidades alternativas en contextos de violencia.

Palabras clave: masculinidades no violentas, masculinidad hegemónica, comunidades pentecostales de base, pandillas juveniles guatemaltecas.

\footnotetext{
* As informações que serviram de base para a redação deste texto foram extraídas do artigo publicado na revista Fe y Pueblo (Román-López Dollinger, 2014b) e do trabalho apresentado na Universidade Bíblica da América Latina (Román-López Dollinger, 2017).

** La información que sirvió de base para escribir este texto se tomó del artículo que se publicó en la revista Fe y Pueblo (Román-López Dollinger 2014b) y de la ponencia presentada en La Universidad Bíblica Latinoamericana (Román-López Dollinger 2017).
} 
Abstract: extremely violent male contexts, such as the Guatemalan youth gangs, Pentecostal communities offer interesting alternatives to young gang members out of violence. Reflect biblical and theologically on the impact of these alternatives can help the Church to confront the pastoral challenges involving the construction of alternative masculinities in contexts of violence.

Key words: non-violent masculinities, hegemonic masculinity, pentecostal base communities, Guatemalan youth gangs.

\section{Introducción}

Hablar del pentecostalismo como posibilidad para construir masculinidades no violentas parece ser una tarea complicada y, para algunas personas, quizá hasta contradictoria. Sin embargo, esa dificultad metodológica se supera cuando el pentecostalismo y las masculinidades no se reducen a categorías abstractas, sino a acciones concretas y sujetos específicos que se intersectan en un momento de su historia para proponer y construir modelos alternativos de ser hombres. En otras palabras, para comprender el aporte del pentecostalismo a la construcción de masculinidades no violentas, no es conveniente partir de doctrinas o teologías pentecostales ni de formulaciones teóricas sobre masculinidades. Más bien hay que tomar como base las prácticas concretas de la pastoral pentecostal y su impacto en las conductas masculinas. Por supuesto que esto no implica evadir la responsabilidad de abordar las teorías y estudios teóricos sobre el pentecostalismo y las masculinidades, pues eso ayuda a comprender mejor el aporte pentecostal a la construcción de masculinidades no violentas.

En ese sentido, cabe señalar que el pentecostalismo ha sido considerado como uno de los fenómenos religiosos más importantes de Latinoamérica. Esto obedece a que su consolidación y crecimiento -especialmente en sectores empobrecidos- ha interpelado no solo las estructuras religiosas tradicionales y sus formas de comprender y practicar la fe cristiana, sino también la masculinidad hegemónica tradicional. Para este movimiento la vida en el Espíritu (pentecostalidad) se constituye en un tipo de reforma religiosa para los grupos empobrecidos, en cuanto les motiva a generar cambios significativos en el orden cultural, social y personal.

Si bien a primera vista la doctrina pentecostal pareciera validar y consolidar la masculinidad hegemónica tradicional, al observar detenidamente la pastoral de sus comunidades de base, se pueden detectar ciertas prácticas cotidianas que fomentan conductas no violentas en los hombres y relaciones de género equitativas en las comunidades. 
Para las comunidades pentecostales de base el objetivo del cambio de conductas en los hombres es superar problemas relacionados con el modelo tradicional de ser hombre: alcohólico, machista y violento. Para lograr ese objetivo proponen un modelo masculino centrado en la imagen de Jesús: no violento, tierno, sensible, servicial.

Por su parte, la teoría de género y diversos aportes feministas han estimulado procesos profundos de reflexión sobre "ser hombre" y "ser mujer". Esta situación ha generado que también algunos hombres comencemos a reflexionar sobre formas alternativas de vivir nuestras masculinidades. Es así como poco a poco vamos tomando conciencia que el modelo masculino hegemónico vigente no funciona. Sin embargo, no es suficiente reconocer la ineficacia de ese modelo -aunque es un buen primer paso-, sino también es necesario pensar en alternativas creativas y subversivas que permitan cambiar ese modelo por modelos alternativos y liberadores.

En contextos sumamente violentos, como el guatemalteco, donde muchos hombres jóvenes de barrios marginales se adhieren a pandillas y realizan actividades criminales y violentas, las comunidades pentecostales de base ofrecen alternativas importantes para que estos jóvenes cambien sus conductas masculinidades. Reflexionar bíblica y teológicamente sobre el impacto de esas alternativas puede ayudar a la iglesia a enfrentar los desafíos pastorales que implican las masculinidades alternativas emergentes, tarea que evidentemente no ha sido tratada a profundidad por la teología Latinoamérica.

Sobre la base de lo expresado arriba se plantea el objetivo de estas reflexiones: visibilizar algunas experiencias de grupos pentecostales de base que, a través del trabajo pastoral con pandilleros en contextos urbanos marginalizados de Guatemala, han logrado desarrollar procesos terapéuticos que ayudan a transformar conductas masculinas violentas en conductas sensibles. Para lograr tal objetivo, el presente artículo aborda cuatro temas que se cruzan en el análisis: 1) Relaciones de poder y género. 2) Pandillas juveniles en Guatemala. 3) El pentecostalismo como fenómeno religioso. 4) Comunidades pentecostales de base en Guatemala. 5) Nuevas masculinidades en las comunidades pentecostales de base.

\section{Relaciones de poder, género y socialización religiosa}

Cuando se analiza el tema de la(s) masculinidad(es), independientemente del contexto en el que se haga (familiar, laboral, escolar, 
eclesial), no se puede evitar recurrir a la categoría género y, sobre todo, a las relaciones de poder implícitas en ella. Desde hace varios años se ha abordado el tema del poder desde diferentes perspectivas y disciplinas académicas. ${ }^{1}$ Sin embargo los aportes del feminismo son los que más influencia han tenido en la reflexión actual sobre el tema del poder en las relaciones de género. ${ }^{2}$

La importancia de analizar las masculinidades desde el poder se justifica en que las relaciones de género -en la vida cotidiana, política, económica, cultural- están condicionas por modelos sociales y culturales, donde hombres adultos ejercen dominio y control sobre los otros sujetos sociales. Aunque el poder se puede abordar desde la macro-estructura social, últimamente y gracias a la perspectiva de género se ha puesto mayor énfasis en las esferas particulares y cotidianas de dominio y control de las personas. Esto es fundamental porque solo desde esas esferas se comprende el papel real y directo del poder en nuestras vidas, conductas, decisiones y formas de controlar y dominar nuestras relaciones (Connell 1997:37; Foucault 1987:26-31, 1999:41-55).

Ahora bien, las masculinidades y feminidades son temas que competen a hombres y a mujeres, ya que esas relaciones se construyen socialmente con la participación de ambos géneros y con el apoyo de las instituciones socializadoras: familia, escuela, iglesia. En estas instituciones se aprende a ejercer dominio y control sobre personas más débiles (Román-López Dollinger 2015). Aunque la familia y la escuela juegan un papel muy importante en la revalidación de estereotipos masculinos tradicionales o en la construcción de nuevas formas de vivir la masculinidad, aquí nos concentraremos más en la socialización que ejerce la iglesia. Esto con el fin de poder vincular más adelante el aporte que las comunidades pentecostales de base hacen a la construcción de masculinidades alternativas, no violentas y sensibles.

Según algunos estudios de género (Hartley 1959; Lagarde 1997; Oakley 1972; Stoller 1968), para comprender la función de las insti-

Algunos de esos aportes están representados por disciplinas como la filosofía (Foucault 1987, 1999; Nietzsche 2009), economía (Marx 1980, 2005), política (Michels 1969, 2008), sociología (Bourdieu 2000; Izquierdo Brichs y Kemou 2009; Weber 1964, 1999), psicología social (French y Raven 1972), pedagogía (Freire 1970, 1981, 1990), teología (Boff 1975; Comblin 1988; Gutiérrez 1975).

2 Algunos de esos aportes son los estudios realizados por Amy Allen (1998, 2000, 2009), Simone de Beauvoir (1949), Judith Butler (2001, 2007), Nancy Hartsock (1983), Marcela Lagarde (2005, 2012); Ivone Gebara (1994, 2002), Amelia Valcárcel $(1994,1997)$ y Elisabeth Schüssler Fiorenza $(2004,2008,2011)$. 
tuciones socializadoras en la construcción de masculinidades es importante tomar en cuenta tres elementos que condicionan cualquier socialización humana: 1) La asignación del género, que se da al nacer. 2) La identidad de género, expresada en factores biológicos y psicológicos, los cuales condicionan la personalidad para que se identifique con el género asignado. 3) El rol de género, el cual determina cuáles actividades o áreas de acción corresponden a uno u otro género.

Ahora bien, para que la socialización sea efectiva es necesario que las personas acepten el rol de género que se les ha asignado (Bourdieu 2000; Connell 1997:44-77). Es aquí donde entran a funcionar las instituciones socializadoras, las cuales facilitan la aceptación de los roles de género tradicionales.

La iglesia, como institución socializadora, es un espacio que por tradición promueve y reproduce modelos masculinos hegemónicos, donde se le otorga al hombre todo el poder (dominio y control) sobre la mujer, el hogar, las hijas y los hijos. La ética cristiana tradicional patriarcal generalmente influye a otras instituciones socializadoras: la familia, la escuela y el trabajo. Por esa razón, aunque muchas personas no asistan a una iglesia o no se consideren cristianas, están permeadas por esa ética religiosa. Este aspecto refleja la importancia de trabajar el tema de las masculinidades desde la socialización religiosa.

En nuestro caso, para abordar esa temática, se toma como ejemplo la experiencia pastoral de algunas comunidades pentecostales de base con jóvenes pandilleros de barrios empobrecidos y marginalizados de Guatemala. Es por ello que antes de analizar el pentecostalismo y la pastoral de sus comunidades de base, es pertinente hacer un breve análisis sobre las pandillas juveniles en Guatemala.

\section{Pandillas juveniles en Guatemala}

En los barrios empobrecidos y marginalizados de la ciudad de Guatemala, las personas jóvenes viven y crecen en contextos que no les ofrecen posibilidades reales para lograr vivir de forma digna y justa. Por otro lado, en estos contextos, las personas jóvenes están en constante relación con situaciones peligrosas, relacionadas con hechos delincuenciales, consumo y tráfico de sustancias prohibidas y criminalidad. Según algunos estudios, esa es la razón por la que muchas personas jóvenes se ven motivadas a ingresar a una pandilla del barrio (Loudis et al. 2006; Román-López Dollinger 2014a; Román-López Dollinger y 
Weltert 2013). Las pandillas proporcionan a estas los medios materiales (alimentación, vivienda, dinero) y subjetivos (estatus, identidad, protección) para que puedan sobrevivir en sus contextos adversos. Por esa razón, muchos jóvenes deciden ingresar a una pandilla a pesar de los riesgos que ello implica, especialmente cuando estos grupos realizan actividades criminales.

En Guatemala es común que los problemas sociales relacionados con consumo y tráfico de sustancias prohibidas, así como la violencia criminal se atribuyen mayormente a personas jóvenes -especialmente a jóvenes pandilleros (ONUDD 2007a:62; USAID 2006:16-18, 20-23, $34 \mathrm{~s}$ ). En Centro América, las pandillas se conocen como maras. ${ }^{3}$ Sin embargo, no todos los grupos juveniles que se autodefinen como maras son pandillas criminales institucionalizadas, aunque presenten actitudes antisociales o realicen hechos delictivos esporádicos. Esto obedece a las siguientes razones: su membrecía se reduce a sus miembros actuales, sus actividades delictivas son locales y asistemáticas, no tienen continuidad institucional y no exigen de sus miembros dedicarse completamente al crimen.

Por su parte, una pandilla criminal es una agrupación institucionalizada, donde su membrecía actual tiene continuidad -a veces por varias generaciones-, tiene su propio conjunto de reglas, formas de reunión, sistemas de categorización (grados de poder), ritos de iniciación, admisión y de muerte. Su filosofía se fundamenta en la lealtad a la pandilla, la cual interpreta como una familia extendida. ${ }^{4}$ Regularmente los miembros de una pandilla viven en el mismo barrio, desde donde coordinan sus actividades delictivas y al cual consideran su territorio. ${ }^{5}$ Las pandillas exigen de sus miembros actividades criminales y les

\footnotetext{
La palabra mara es el diminutivo de "marabunta", nombre de una hormiga roja salvaje muy peligrosa y destructiva (Smutt y Miranda 1998:25). En Centro América, la palabra se comenzó a usar en la década de 1970, por una película donde esas hormigas destruyen una región de Brasil (Haskin 1954). En Guatemala la palabra se emplea como sinónimo de "mis amigos", "mis compañeros", "mis iguales", “mi familia” (Fischer 2005:1s; Merino 2001:112; Peetz 2004:60; Zinecker 2006:8).

4 Estos dos elementos (lealtad y familia) resultan muy atractivos para jóvenes que provienen de contextos donde sus familias reales están ausentes o son disfuncionales. La lealtad va unida a la identidad de grupo y se expresa en la vestimenta, grafitis, tatuajes, sobrenombres y un lenguaje especial, verbal y no verbal (Santacruz Giralt y Cruz Alas 2001:37-46).

5 La relación con el territorio (barrio) que dominan es de protección-opresión. La protección es a menudo obligatoria y se realiza a través de la extorsión que obligan a pagar a las personas con alguna actividad lucrativa en el barrio (ONUDD 2007a:62; Santacruz Giralt y Cruz Alas 2001:55$62,64-69)$.
} 
inculcan una actitud de oposición a la ley. A menudo sus miembros cometen crímenes solamente para demostrar lealtad a la pandilla y no para obtener algún beneficio económico. Por esa razón, leyes duras antipandillas difícilmente los disuaden (ONUDD 2007a:62s).

Hay diferentes enfoques que intentan explicar el surgimiento y desarrollo de las maras. Uno de ellos es el socio-ecológico, que plantea que las maras son el resultado de la desorganización de las zonas urbanas, lo cual a menudo destruye las instituciones sociales tradicionales como la familia y las reemplaza parcialmente por otras alternativas, como las pandillas o las maras. El enfoque cultural explica este fenómeno como una subcultura que surge de las clases urbanas empobrecidas. Algunas teorías económicas proponen que las maras son producto de la necesidad de la juventud pobre de realizar actividades laborales, las cuales encuentran en grupos identificados con el tráfico de sustancias y con el crimen organizado (Poljuve 2009:7). Asimismo, los enfoques psicológicos intentan explicar el ingreso a una pandilla como parte de un proceso de maduración y formación de la identidad de niños y jóvenes (Rodgers 2003).

Cada uno de esos enfoques aborda aspectos diferentes de las pandillas, pero en la realidad este fenómeno integra todos ellos. Hay estudios que afirman que las pandillas juveniles o maras son resultado de la exclusión social y de la "violencia estructural" (Anderson 1999; Spergel 1995, 2002). Otros estudios complementan los anteriores indicando que la violencia estructural genera en las personas excluidas una violencia reactiva en forma criminal o política. Es decir, las condiciones de miseria, frustración y desesperación son un potencial para el surgimiento de grupos violentos y delictivos (Briceño-León y Zubillaga 2002).

Hay quienes sostienen que el origen de las maras centroamericanas se encuentra en Estados Unidos, específicamente en el estado de California, donde jóvenes migrantes empobrecidos latinoamericanos formaron pandillas con estructuras criminales complejas (ONUDD 2007a:63; Savenije 2007:638-40; USAID 2006:16-20). Otros estudios rechazan ese enfoque, pues con ello dan un carácter transnacional a esos grupos y los vinculan directamente con el crimen organizado. Eso no solo justifica las políticas de "mano dura" contra jóvenes marginalizados, sino con ello se esconden los problemas estructurales locales que permiten y facilitan la presencia de maras o pandillas criminales: pobreza, desigualdad social, limitado acceso a educación, salud, vivien- 
da, etc. (Peetz 2004:55s; Román-López Dollinger 2013; Savenije 2007). Sin embargo, aunque el fenómeno de las maras en Guatemala es muy complejo y su origen puede ser diverso, no se puede negar la influencia de las pandillas de Estados Unidos. Por esa razón es importante conocer más de cerca cómo se forma la identidad de esos grupos.

Se estima que California es el punto tradicional de asentamiento en los Estados Unidos para migrantes hispanos. Por ejemplo, en ciudades grandes como Los Angeles, hay barrios que, a pesar de su composición nacional variada, han sido hispanoparlantes por generaciones. Hasta la década de 1980, el área Rampart de los Angeles era dominada por pandillas mexicanas (ONUDD 2007b:180). ${ }^{6}$ En este barrio operaba la pandilla de la Calle 18 desde la década de 1960. En la década de 1980 comenzaron a llegar a ese barrio jóvenes salvadoreños refugiados, quienes tuvieron que decidir entre unirse a la pandilla de la Calle 18 o formar una propia pandilla para defenderse. Es así como algunos jóvenes optaron por formar la pandilla que ahora se conoce como Mara Salvatrucha. Así nació la tradicional rivalidad entre estos grupos. En la década de 1990 esa rivalidad se trasladó a Centro América, cuando varios jóvenes de esas pandillas fueron deportados a sus países (ONUDD 2007a:64s).

En el caso de Guatemala los grupos juveniles criminales ya existían antes del conflicto armado interno y se conocían como "pandillas". Pero fue hasta la década de 1960, paradójicamente junto con al inicio del conflicto armado interno, que cobraron relevancia. Al inicio de la década de 1980 se les comenzó a denominar "maras" y sus actividades ya se caracterizaban por altos grados de violencia, la que aumentó en la década de 1990, posiblemente por la confluencia de dos factores: 1) La llegada de varios jóvenes deportados de Estados Unidos. 2) El final del conflicto armado interno, el cual dejó grandes cantidades de personas desocupadas, tanto del ejército como de la guerrilla, con experiencia en el uso de armas y tácticas de guerra.

Se estima que en los primeros años del siglo XXI ya existían en Guatemala aproximadamente 434 agrupaciones reconocidas como maras, las cuales aglutinaban alrededor de 14,000 miembros, para un

El barrio de Rampart fue considerado el más peligroso de Estados Unidos. Abarca ocho millas cuadradas al oeste del centro de Los Ángeles. Para el año 2006 tenía más de 375,000 residentes y unos 350 oficiales de policía. En este barrio se concentra la mayor cantidad de pandillas de Los Ángeles: unas sesenta pandillas, con un total de ocho mil miembros (ONUDD 2007b:180). 
promedio de 32 jóvenes por pandilla (ONUDD 2007a:64s). ${ }^{7}$ No se puede afirmar que el grado de institucionalización e internacionalidad de estos grupos sea elevado, pues lo más seguro es que solamente algunos de ellos alcanzan un grado complejo de organización criminal y transnacional, especialmente los que tienen contacto con el crimen organizado. La mayoría de estos grupos siguen siendo locales y sus miembros se dedican a actividades delincuenciales no institucionalizadas. ${ }^{8}$

Tanto el Estado como la sociedad civil de Guatemala implementan diferentes estrategias para combatir y prevenir la violencia y el crimen juvenil. Estas estrategias tienen dos formas: reactivas o preventivas.

Las políticas reactivas se centran en la persecución y control legal, a través de la creación de leyes "anti-maras", detenciones masivas de jóvenes que cometen delitos, imposición de penas drásticas y programas de rehabilitación. Esta perspectiva entiende la violencia juvenil (especialmente de maras y pandillas) como una amenaza para la seguridad pública, pues la vincula directamente con el crimen organizado (Curran y Renzetti 2001; Loudis et al. 2006). Regularmente estas estrategias derivan en violaciones a los derechos humanos a través de tortura, violación sexual y ejecuciones extrajudiciales por parte de agentes de las fuerzas de seguridad del Estado o grupos afines a éstos (Moser, Winton, y Moser 2005; Peacock y Beltrán 2004; Spergel 1995).

Las políticas preventivas se orientan a evitar o reducir los riesgos de actos violentos o delictivos. Entre este tipo de enfoques sobresalen los siguientes: de salud pública, de desarrollo, de derechos humanos, sociológico-criminológicos y de transformación de conflictos. Estos enfoques buscan prevenir y reducir los riesgos y costos sociales de la violencia y criminalidad a través de programas de rehabilitación y prevención, reformas y ajustes económicos, monitoreo de las acciones del Estado y denuncia de los abusos de agentes estatales, análisis de las causas estructurales de los conflictos, y el establecimiento o restablecimiento de las relaciones disfuncionales a través de intervenciones sanas en la solución de conflictos (Poljuve 2009:8-11).

Según esa fuente, para esos años en Centroamérica ya existían unas 924 pandillas, con un total de 69.149 miembros, divididas como sigue: Honduras 36,000 miembros, distribuidos en 112 pandillas. El Salvador 10,500 miembros distribuidos en 4 pandillas. Otras fuentes afirman que el número de pandilleros en Guatemala, Honduras y El Salvador oscilaba entre 200,000 y 500,000 (FAP 2006:12; Peetz 2004:58-60).

8 Algunos estudios que analizan el grado de responsabilidad de las pandillas en el aumento del crimen en Guatemala, confirman esta suposición (PDH 2004; Ranum 2006:27-30). 


\section{El pentecostalismo como fenómeno religioso}

Es indiscutible que desde mediados del siglo pasado el movimiento pentecostal se ha constituido en un fenómeno religioso de gran envergadura en Latinoamérica. ${ }^{9}$ Su presencia, consolidación y crecimiento ha generado mucho interés en diferentes ámbitos académicos y perspectivas teóricas, las cuales parten básicamente de los siguientes supuestos:

- Es una expresión renovada de las tradiciones religiosas y espirituales populares de Latinoamérica, donde personas empobrecidas encuentran alternativas de adaptación al mundo globalizado (Bastian 1983, 1986, Rolim 1980, 1985, Sepúlveda 1992, 2009; Willems 1967).

- Ofrece refugio a personas empobrecidas que, por la rapidez de los cambios sociales, se encuentran en un estado de anomía social ${ }^{10}$ lo cual les ayuda a convivir con la modernidad sin dejarse absorber completamente por ella (Lalive D’Epinay 1968; Schäfer 2009; Stoll 1993).

- Genera resiliencia psicológica colectiva, pues ofrece espacios de identidad, protección y pertenencia que ayudan a enfrentar la despersonalización del mundo urbano moderno (Álvarez 1992:85-83; Bergunder 2009a:7-11; Míguez Bonino 1995:6163; Sepúlveda 1992:78-82).

- Es un avivamiento espiritual que interpela al cristianismo latinoamericano tradicional y que llena el vacío religioso que dejó especialmente la iglesia católica (Hurtado Cruchaga 1941; Vergara 1962).

- Promueve la participación activa de sus miembros e integra sus diferentes expresiones culturales y religiosas de corte popular (Álvarez 1992, 2006; Schäfer 1992).

$9 \quad$ En el continente están presentes por lo menos tres corrientes del pentecostalismo (Álvarez 2006:19-30; Schäfer 2009; Smith 2006): 1) Pentecostalismo criollo, se forma en Chile y Brasil entre 1907 y 1909. 2) Pentecostalismo misionero, se establece en Argentina en 1914 como misión de las Asambleas de Dios de Estados Unidos. 3) Pentecostalismo de sanación divina y prosperidad, surge en los años 1990s como un tipo de consumismo religioso a través de música, danzas, exorcismos, profecías, sanaciones multitudinarias, etc.

10 La anomía social se refiere a la falta o pérdida de la adecuada jerarquización de los valores culturales y/o sociales, debido a cambios drásticos en las estructuras sociales. Implica la incapacidad de las instituciones sociales y del Estado de proveer los medios básicos para que las personas se realicen plenamente dentro de los modelos que exige la sociedad: trabajo, vivienda, educación, ocio, etc. (Durkheim 2003; Merton 1964). 
El pentecostalismo es un fenómeno religioso que no se puede entender reduciéndolo a un movimiento monolítico o considerándolo una herejía (Astete y Sálesman 2006) o pensando que es una secta con intereses religiosos fundamentalistas (Hill 1976; Masferrer Kann 2004; Stoll 1993:362-67). ${ }^{11}$ El pentecostalismo es más bien un fenómeno religioso, social-cultural y dinámico que se encuentra en constante desarrollo y está formado por diversos grupos cristianos con diferentes formas de expresión, organización, teología, doctrina y culto.

Lo que sí existe son elementos comunes, prácticos y doctrinales que confieren a esas agrupaciones religiosas una identidad propiamente pentecostal, por ejemplo: 1) Bautismo en el Espíritu (Santo) como señal de conversión y renacimiento en Cristo. 2) Infalibilidad bíblica y su lectura comunitaria. 3) Testimonio personal sobre la acción de Dios en la vida cotidiana. 4) Guerra espiritual contra espíritus abstractos (tentaciones, pecado, mal) y espíritus físicos (enfermedades, pobreza, violencia). 5) La prosperidad personal (salud, trabajo, educación) que genera el compromiso con Dios (diezmo, ofrenda, servicio). 6) Su presencia en sectores empobrecidos y marginalizados, lo cual justifica que sus miembros provengan mayormente de las clases populares. 7) Formación de grupos (células o comunidades) de base.

El tipo de proyección y compromiso social (pastoral) de los grupos pentecostales en sectores populares, depende del énfasis que pone en cada uno de esos elementos.

El fenómeno religioso pentecostal ha generado la revisión de dos categorías fundamentales relacionadas con las formas de comprender y practicar la religión: los ritos y las creencias. A través de su comprensión (creencias) de la realidad concreta (profana) y la realidad ideal (sagrada), el pentecostalismo desarrolla reglas de conducta y prácticas religiosas cotidianas, generalmente en formas de ritos, que permite a sus miembros mantener una relación equilibrada con lo sagrado. Esas conductas y prácticas implican rechazar selectivamente aspectos profanos que puedan poner en peligro la relación con lo sagrado. Eso es importante porque, en el caso de los hombres, promueve cambios de conducta que les motiva a vivir una masculinidad sagrada (alternativa) que se opone a la masculinidad profana (hegemónica) que "el mundo" (la sociedad) exige.

11 Estas percepciones negativas del pentecostalismo, generalmente dificultan que se pueda analizar el aporte que este movimiento hace a la religión, la cultura, teología y sobre todo a la pastoral (Álvarez 2006; Schäfer 2009). 
Es en este sentido que se puede afirmar que el pentecostalismo se constituye en un tipo de reforma religiosa que interpela no solo las estructuras eclesiales tradicionales, sino también sus formas de comprender y practicar la fe cristiana y -quizá sin proponérselo- las formas patriarcales de las relaciones de género, especialmente cuando propone una masculinidad alternativa centrada en la figura de Jesús.

\section{Comunidades pentecostales de base en Guatemala}

En Guatemala, así como en toda Latinoamérica, las manifestaciones religiosas populares son expresiones sociales que ponen de manifiesto una relación dicotómica e indisoluble entre la "religión popular" y "la religión oficial". Esto ocurre en todas las corrientes religiosas cristianas establecidas oficialmente en la sociedad. En el pentecostalismo también están presentes este tipo de manifestaciones populares.

Junto a las diferentes corrientes pentecostales establecidas oficialmente en Guatemala, existen grupos populares que surgieron de esas corrientes o que se identifican teológica y/o doctrinalmente con alguna de ellas. Estas agrupaciones son a las que denominamos "comunidades pentecostales de base" y tienen las siguientes características: 1) Se ubican en sectores empobrecidos (urbanos y rurales). 2) No cuentan con un templo, se reúnen en casas particulares o salones de iglesias. 3) Surgen de "células" (grupos) de estudio bíblico. 4) Sus líderes provienen de esas células de estudio. 5) No dependen de una iglesia específica y por ello gozan de autonomía eclesial (Román-López Dollinger 2014b).

Según algunos datos cualitativos recolectados en algunos barrios de la ciudad de Guatemala (Román-López Dollinger 2014a), las personas que forman parte de estas comunidades de fe, se comprometen a cumplir las normas y valores del grupo, lo cual implica iniciar un proceso de cambio de conducta que tenga efecto en su entorno: familia, amistades, colegas. Además, se consideran una familia extendida (Frei 2011:224-53; Ullán de la Rosa 2003:242-53).

La razón de denominar a estos grupos "comunidades pentecostales de base" obedece a las similitudes que tienen con las "comunidades eclesiales de base" (CEBs) católicas. ${ }^{12}$ Entre esas similitudes se pueden mencionar las siguientes:

\footnotetext{
12 Las CEBs surgieron en el seno de la iglesia católica, a través del compromiso de ciertos sectores eclesiales que se identificaban con la teología de la liberación. Las CEBs intentaron dar respuestas pastorales a las necesidades religiosas, sociales, culturales y económicas de personas que vivían en contextos conflictivos. Su recepción fue muy fuerte en países con regímenes represivos y con conflictos armados internos.
} 
- Son una opción atractiva y efectiva para personas empobrecidas, pues tienen estructuras y relaciones que promueven el cambio social a través de la participación activa de sus miembros en los problemas de su contexto (Álvarez 2006; Bergunder 2009b; Moltmann y Kuschel 1996; Schäfer 2009).

- Promueven el empoderamiento y la resiliencia de personas empobrecidas, al motivarlas a trasformar sus vidas personales y su contexto a partir de sus propias capacidades. Les hace sentir que son parte de la solución a sus problemas (Sepúlveda 2009:110).

- Sus miembros se comprometen pastoralmente con las necesidades de las personas que comparten su condición de empobrecimiento (Boff 1979; Dussel 1998; Gutiérrez 1977; Hinkelammert 1998; Pixley y Boff 1986).

\section{Nuevas masculinidades en las comunidades pentecostales de base}

Las siguientes reflexiones se limitan a la experiencia pastoral de comunidades pentecostales de base y se fundamentan en datos cualitativos recolectados a través de entrevistas narrativas realizadas con hombres pentecostales entre 24 y 29 años, quienes en el pasado vivieron experiencias de violencia en pandillas y actualmente coordinan la pastoral de la calle de algunas comunidades pentecostales de base. ${ }^{13}$

Los datos reflejan los procesos de conversión (rehabilitación) de estas personas y el consecuente cambio de conducta (resocialización) en sus relaciones de género. A partir de sus procesos de conversión estos jóvenes tuvieron la oportunidad de vivir, sentir, pensar y expresar una masculinidad no violenta. Su trabajo pastoral actual consiste en trasladar esa nueva forma de "ser hombre" a hombres jóvenes que por su condición de marginalidad son susceptibles a convertirse en hombres violentos.

\section{La conversión pentecostal}

Muchos hombres jóvenes marginalizados con conductas violentas encuentran en las comunidades pentecostales de base espacios de

La información se obtuvo de grupos que trabajan con pandillas en Guatemala y fue recolectada entre los años 2007 y 2012, enriquecida y depurada en los años 2015 y 2016 (Román-López Dollinger 2014a). 
refugio seguros, identidad colectiva, educación, diversión y procesos terapéuticos que les ayudan a superar sus problemas de conducta. Son espacios de refugio para sus problemas cotidianos (Lalive D'Epinay 1968; Schipani 1997; Sepúlveda 2009:113-15). El primer paso para iniciar un proceso terapéutico en estos grupos es "aceptar a Cristo", es decir la conversión.

En cada grupo, en cada movimiento hay una cierta rutina de aceptación, es una decisión personal. (...) Cuando uno mismo toma la decisión de rendir, entregar toda su vida a Dios, a través del sacrificio que Jesucristo ha hecho por nosotros. Después de esa decisión ya pasa uno a formar parte de la familia pente (Oscar).

Este rito de iniciación (conversión) es un paso muy significativo para hombres jóvenes con experiencias de violencia, pues implica fidelidad al grupo y cambio de conducta. Como se observa en la siguiente cita, este proceso de iniciación ya lo han vivido al ingresar a una pandilla:

Una pandilla o mara es como una familia (...) cuando ingresé a la pandilla me sentí así, como en una familia, una familia de verdad. No como mi familia sanguínea, fragmentada y con malos ejemplos, sin que les importara que me pasaba. Por eso acepté entrar a la pandilla y hacer lo que me pedían, hasta estaba dispuesto a dar mi vida por ella. Y ellos me dieron protección, amistad, inclusive un estatus. (Jorge).

En el contexto de iglesia, el rito se mantiene, inclusive conserva algunos símbolos: familia, protección, amistad y reconocimiento. Lo que cambian son los contenidos prácticos del rito y los símbolos:

La iglesia pentecostal me ha hecho sentir que Cristo está tan cerquita, que puede ser mi compadre (amigo solidario), mi cuate (gran amigo), que no es solo para gente de élite. (...) Ahí encontré una familia, cariño y apoyo. (...) Nadie me llamó pandillero, sino me dijo mi nombre y me enseñaron que yo mismo soy la iglesia... Y yo ahí mismo me vi refugiado y acepté cambiar mi vida... (Fernando).

La conversión es un tipo de terapia que, junto a la empatía de la comunidad abre la posibilidad para que jóvenes violentos decidan cambiar sus vidas (conductas).

\section{La amistad como terapia comunitaria}

Aunque estas comunidades generalmente no cuentan con centros de rehabilitación, tienen criterios terapéuticos flexibles y claros para 
acompañar jóvenes con conductas violentas. El segundo paso terapéutico, inmediatamente después de la conversión, consiste en brindarle a la persona la amistad de la comunidad de fe.

Nosotros ahorita tenemos a una persona que en una actividad de nosotros él recibió a Cristo (se hizo cristiano), ¿verdad?, como le llamamos nosotros, "la iniciación". Entonces, nosotros hemos empezado una terapia con él. Pero la terapia no es algo técnico escrito, sino lo que hemos empezado a hacer es acercarnos y brindarle nuestra amistad. Y yo siento que esto podría ser como cierta terapia, porque él definitivamente no conoce a ninguna otra persona que considere su amigo (Fernando).

La amistad es un instrumento terapéutico fundamental, pues muchos jóvenes involucrados en pandillas tienen problemas en sus relaciones interpersonales y les cuesta construir lazos de amistad sólidos con otros hombres. La amistad sensibiliza a los jóvenes para que comiencen a hablar con sus amigos sobre sus problemas y temores:

Nosotros tratamos de darle nuestra amistad o la "leche espiritual", como le llamamos. Lo llevamos a jugar básquet a la cancha y a nuestras reuniones, también a cultos en diferentes iglesias, lo invitamos a comer, a un refresco. Tratamos que sienta que no está solo, que somos sus amigos y lo queremos. Eso lo veo como una terapia, pues él ha comenzado a abrir su corazón y a hablar de sus cosas personales (Fernando).

La amistad permite escuchar los sueños y esperanzas de los jóvenes, solidarizarse comunitariamente con ellos y buscar alternativas de rehabilitación y reinserción social. Es un acto de solidaridad-amistad humana (Galilea 1997; Johns 2009).

\section{Expresar los miedos y sensibilidades masculinas}

Los hombres -y especialmente los hombres violentos- están constantemente enfrascados en una lucha por no demostrar sus miedos y "debilidades" (sensibilidades). Reprimir el miedo genera en los hombres jóvenes actitudes violentas, lo cual les hace perder paulatinamente la sensibilidad frente al dolor de otras personas. El siguiente ejemplo refleja esta situación:

La primera vez que yo vi sangre, yo estaba en la pandilla, y quería ser parte de ella, parte de un grupo, por las cosas que se daban fáciles, dinero, mujeres, respeto, muchas cosas, en el barrio, en la colonia... Pero entonces tenía que hacer cosas que en el fondo me daban miedo, tenía que golpear a alguien de otra pandilla, solo para demostrar mi fidelidad al grupo. La primera vez que golpeé a alguien y vi sangre me impactó, me dio miedo, pero no lo demostré. Luego 
fui perdiendo el miedo y ya me valía madre (no me importaba). Es más, le fui agarrando el gusto (Jorge).

Sin embargo, a través de procesos terapéuticos en contextos pentecostales de base, estos jóvenes violentos logran recuperar su sensibilidad y comienzan a construir una nueva forma de ser hombres, donde el miedo y las sensibilidades ya no son aspectos negativos.

Hoy en día miro mi vida como una película y yo digo: a la gran (increíble), hasta donde yo estaba perdido. Y me da tanto miedo pensar lo que hice. La otra vez hablando con Jorge de las cosas que hicimos nos dimos cuenta que los dos tenemos miedo de lo que los hombres podemos hacer. Ese día hasta chillamos (lloramos) juntos, nos abrazamos y oramos juntos. (...) Llorar y orar juntos nos ha ayudado a ser mejores hombres cada día, como dice Pablo cada día enterramos una parte de nuestro "hombre viejo" y le damos vida a nuestro "hombre nuevo" en Cristo (Oscar).

Expresar los miedos y sensibilidades masculinas entre hombres es un instrumento significativo de la pastoral pentecostal, que puede ayudar a construir masculinidades no violentas.

\section{Relaciones equitativas de género}

El aporte que las comunidades pentecostales de base hacen a la construcción de masculinidades no violentas se evidencia en el cambio de percepción de los hombres con respecto a las mujeres. Tener un proceso de conversión, experimentar relaciones profundas de amistad con otros hombres y expresar los miedos y sensibilidades, permite que hombres que tuvieron actitudes violentas hacia las mujeres, logren cambiar su actitud hacia ellas. Las siguientes secuencias de citas, ofrece un ejemplo de este cambio de conducta. ${ }^{14}$

Secuencia 1

Antes para mí las mujeres solo eran para tener sexo, para ir a recoger el dinero de nuestros negocios y para guardarnos nuestras cosas (armas). (...) También tenía la idea que solo a golpes entendían y pensaba que les gustaba que uno las golpeara (Oscar).

Ahora, en nuestro ministerio, yo trabajo junto a mi esposa. Ella tiene su propio espacio en el ministerio. Va a los hospitales y a los asilos. En las noches cocinamos y comemos juntos, acostamos a nuestra nena (hija), oramos juntos y hablamos del ministerio (...) Es muy bonito, es una bendición compartir el ministerio con ella (Oscar).

14 Cada una de las partes de la secuencia de las citas se dio en diferentes contextos de la narración. Aquí se ordenaron de acuerdo a los temas de interés. 


\section{Secuencia 2}

Esa patoja (muchacha) traicionó a la pandilla. (...) Entonces, con otro brother (amigo) la vimos subir a un bus y él se subió adelante y yo atrás..., y el bus iba algo lleno... (...) y le comenzamos a pegar como si fuera hombre, sin piedad. (...) Y ella nos dijo que estaba embarazada. Y realmente se le veía algo de panza (vientre). (...) Pero no nos importó, la bajamos a patadas del bus y la dejamos tirada (Jorge).

Yo ahora he aprendido a amar a mi pareja (...) No podría imaginarme golpeándola..., ni a ella ni a otra persona. (...) Yo tengo una hija y no quiero ni pensar que alguien le pueda hacer daño (Jorge).

Estas dos secuencias reflejan el efecto que generan procesos de rehabilitación y reinserción social en las personas y sus relaciones de género. Posiblemente esas nuevas percepciones sobre la masculinidad todavía no tienen una forma reflexiva muy elaborada, pero pueden constituirse en la materia prima para reflexionar las masculinidades desde la perspectiva teológica pentecostal.

\section{Jesús como paradigma masculino}

El cambio de conducta masculina en el pentecostalismo de base no es muy complicado, porque el referente del cambio es la figura de Jesús. Una exigencia pentecostal es seguir a Jesús y tomarlo como modelo de vida. Para hombres que han sido violentos, este aspecto implica un cambio radical en sus vidas, porque tienen que seguir un modelo centrado en la sensibilidad, la ternura y el amor. La siguiente cita refleja el proceso de conversión al pentecostalismo y el consecuente cambio de conducta en jóvenes que provienen de experiencias violentas.

Nosotros veníamos de un estilo de vida totalmente diferente al que íbamos a entrar y que no se puede cambiar de a romplón (totalmente). No es nada más así que hoy me topé (encontré) con Cristo y hoy cambié. Es un proceso que marca el cambio de tu vida, como dice la Biblia "así como se va matando al viejo hombre, va rejuveneciendo el nuevo". (...) Es como si fuéramos bebés de nuevo..., nacemos, crecemos y nos reproducimos. (...) Todo conforme a la voluntad de Dios y de uno, porque de uno depende también, tenés que querer cambiar, si no el hombre viejo sigue vivo (Jorge).

Las siguientes citas reflejan de forma general la imagen que el pentecostalismo de base tiene de Jesús, así como la propuesta de un modelo masculino alternativo. 
Nosotros hemos aprendido que nosotros mismos somos la iglesia y el Señor (Jesús) quiere que la iglesia pentecostal sea la imagen viva de él. (...) El Señor (Jesús) le habló a pescadores en su lenguaje, igual a negociantes, recaudadores de impuestos, sembradores, mujeres de su tiempo..., inclusive a los niños. Se hizo parte de ellos, entró en su contexto y les habló de forma comprensible para ellos. Y eso hace la iglesia pentecostal, te habla en tu idioma y te dice claro que necesitas para cambiar tu vida, por eso te queda cómoda (Fernando).

Jesús quiso mucho a las mujeres, nunca las dañó. (...) Es más, las defendió, acordáte de la adultera. (...) Con los niños fue tierno los cargó y pidió que los dejaran acercarse. (...) Amó a sus amigos (...) a Pedro, a Juan, a Lázaro. Tuvo miedo de morir y lloró sangre. (...) Nunca fue violento, ni siquiera con los que lo torturaron y mataron, es más puso la otra mejía. (...) Seguir a Jesús es querer ser igual a él, hacer lo que hizo, inclusive hasta dar la vida por otros (Jorge).

Cambiar tu vida significa seguir al Señor (Jesús). Eso parece difícil, pero es bien fácil, solamente tenés que decirle al "mundo" que no y cambiar tu forma de ser. (...) Es fácil porque solo tenés que amar a tu prójimo como a ti mismo. (...) Eso nos enseñó el Señor (Jesús) y eso queremos hacer (Oscar).

Si bien el cambio de conducta masculina no es fácil, pues requiere un proceso complicado y, sobre todo, un compromiso personal con el cambio, también es cierto que, con el apoyo de comunidades terapéuticas, como la pastoral pentecostal de la calle, ese proceso se hace más sencillo.

\section{Conclusión}

Las reflexiones que aquí se presentaron posiblemente generan más dudas que respuestas al tema masculinidades. Pero esa es precisamente la situación que enfrentamos actualmente los hombres. Una situación de duda sobre el sentido de "ser hombre" en un contexto donde las relaciones de género y los valores que la sustentan van cambiando radical y aceleradamente. Esto hace que los hombres entremos un estado de anomía masculina o crisis de identidad, provocada por diferentes factores: 1) La interpelación que nos hacen las mujeres a través de la crítica feminista al sistema patriarcal vigente. 2) La convicción cada vez más clara que también somos víctimas del modelo masculino hegemónico. 3) La falta de referentes alternativos para construir una nueva forma de "ser hombres". 4) La dificultad de superar problemas relacionados con violencia. 5) El cansancio físico, mental y emocional que genera la lucha constante y desmedida por alcanzar "el éxito", proveer, dominar y controlar.

Sin embargo, como se pudo apreciar en los testimonios de jóve- 
nes ex pandilleros, en medio de ese panorama desalentador todavía hay luces de esperanza que nos pueden ayudar a construir referentes masculinos alternativos. Por ejemplo: 1) Los aportes teóricos-prácticos que algunas mujeres han realizado para intentar cambiar las formas inequitativas en las relaciones de género. 2) Los incipientes aportes teóricos-prácticos propuestos por algunos hombres que han comprendido que también son víctimas de un sistema que les impone cargar imposibles de llevar. 3) Los aportes pastorales de grupos religiosos, como las comunidades pentecostales de base, que promueven cambios de conducta masculina a través de un modelo centrado en la sensibilidad de Jesús.

Esos aportes reflejan que el tema de las masculinidades alternativas va por el camino correcto en Latinoamérica. En el contexto teológico, algunas de las tareas pendientes para profundizar en el tema son las siguientes:

- Recuperar las experiencias de diferentes grupos religiosos que promueven la equidad de género a través de cambios en la conducta masculina.

- Sistematizar esas experiencias para socializarlas y que se constituyan en criterios teológicos de la pastoral.

- Generar espacios de capacitación sobre teoría de género para personas líderes cristianas, con el fin que trabajen los de equidad de género y masculinidades.

- Trabajar sobre una espiritualidad masculina alternativa centrada en la figura de Jesús plantea: sensible, no violenta, amorosa, transformadora y liberadora.

- Estudiar más de cerca la variedad de experiencias y propuestas religiosas de comunidades de base -pentecostales y no pentecostales- que trabajan el tema masculinidades.

Estas tareas exigen que la iglesia y las demás instituciones socializadoras se comprometan profunda, activa y radicalmente en la construcción de sociedades justas y equitativas, libres de todo tipo de violencia. Solamente ese tipo de sociedades pueden ser un referente concreto de lo que en el contexto cristiano denominamos Reino de Dios. 


\section{Bibliografía}

Allen, Amy. 1998. "Rethinking Power”. Hypatia 13(1):21-40.

Allen, Amy. 2000. The Power of Feminist Theory. Boulder, Colorado: Westview Press.

Allen, Amy. 2009. "Gender and Power". Pp. 293-309 en The SAGE Handbook of Power, editado por S. R. Clegg y M. Haugaard. London: SAGE.

Álvarez, Carmelo. 1992. Pentecostalismo y liberación. Una experiencia latinoamericana. San José, Costa Rica: DEI.

Álvarez, Carmelo. 2006. Alborada de tiempos fecundos. Una teología ecuménica y pentecostal. Quito, Ecuador: CLAI.

Anderson, Elijah. 1999. Code of the Street: Decency, Violence and the Moral Life of the Inner City. New York: W.W. Norton Company.

Astete, Gaspar y Elécer Sálesman. 2006. Nuevo catecismo católico explicado. Según el catecismo de Juan Pablo II. Quito, Ecuador: Editorial San Pablo.

Bastian, Jean-Pierre. 1983. Protestantismo y sociedad en México. México, D.F.: Casa Unida de Publicaciones.

Bastian, Jean-Pierre. 1986. Breve historia del protestantismo en América latina. México, D.F.: Casa Unida de Publicaciones.

Beauvoir, Simone de. 1949. Le deuxième sexe. Paris: Gallimard.

Bergunder, Michael. 2009a. "A modo de introducción. Movimiento pentecostal en América Latina: teorías sociológicas y debates teológicos". Pp. 5-50 en Movimiento pentecostal y comunidades de base en América Latina. La recepción de conceptos teológicos de liberación a través de la teología pentecostal, editado por M. Bergunder. Heidelberg: Universität von Heidelberg.

Bergunder, Michael, ed. 2009b. Movimiento pentecostal y comunidades de base en América Latina. La recepción de conceptos teológicos de liberación a través de la teología pentecostal. Heidelberg: Universität von Heidelberg.

Boff, Leonardo. 1975. Teología desde el cautiverio. Bogotá: Indo-American Press Service.

Boff, Leonardo. 1979. Eclesiogénesis. Las comunidades de base reinventan la iglesia. Santander: Sal Terrae.

Bourdieu, Pierre. 2000. La dominación masculina. Barcelona: Editorial Anagrama.

Briceño-León, Roberto y Verónica Zubillaga. 2002. “Violence and Globalization in Latin America". Current Sociology 50(1):19-37.

Butler, Judith. 2001. Mecanismos psíquicos del poder: teorías sobre la sujeción. Valencia, España: Universitat de València. 
Butler, Judith. 2007. El género en disputa: el feminismo y la subversión de la identidad. Barcelona: Paidós.

Comblin, José. 1988. "El poder de la Iglesia frente a los poderes del mal. El caso de América Latina”. Concilium 217:437-441.

Connell, Robert W. 1997. "La organización social de la masculinidad”. Pp. 31-48 en Masculinidad/es: poder y crisis, Ediciones de la Mujer, editado por T. Valdes y J. Olavarría. Santiago de Chile: ISIS Internacional; FLACSO.

Curran, Daniel J. y Claire M. Renzetti. 2001. Theories of Crime. $2^{\mathrm{a}}$ ed. Boston: Allyn and Bacon.

Durkheim, Émile. 2003. Las reglas del método sociológico. Buenos Aires: Prometeo Libros.

Dussel, Enrique. 1998. Ética de la liberación en la edad de la globalización y de la exclusión. Madrid: Trotta.

FAP. 2006. La cara de la violencia en América Central. Serie: Armas, Violencia y Juventud. San José, Costa Rica: Fundación Arias para la Paz (FAP).

Fischer, Clara. 2005. "Zentralamerikas Maras aus politikwissenschaftlicher Sicht. Ein Beitrag zur Transnationalisierung gesellschaftlicher Konflikte”. Diplomarbeit im Fach Regionalwissenschaften Lateinamerika., Universität zur Köln, Köln.

Foucault, Michel. 1987. Genealogía del Poder. Hermenéutica del sujeto. 7ma. edición. Madrid: Ediciones de la Piqueta.

Foucault, Michel. 1999. Estrategias de poder. Barcelona, España: Paidós. Recuperado 14 de enero de 2016.

Frei, Daniel. 2011. Die Pädagogik der Bekehrung. Sozialisation in chilenischen Pfingstkirchen. Zürich/Berlin: Lit Verlag.

Freire, Paulo. 1970. Pedagogía del oprimido. Bogotá: Editorial América Latina.

Freire, Paulo. 1981. La educación como práctica de la libertad. México D.F.: Siglo XXI.

Freire, Paulo. 1990. La naturaleza política de la educación: cultura, poder y liberación. Barcelona: Paidós.

French, John y Bertram Raven. 1972. "Bases del poder social”. en Dinámica de grupos: investigación y teoría, editado por D. Cartwright y A. F. Zander. México, D.F: Trillas.

Galilea, Segundo. 1997. La amistad de Dios: el cristianismo como amistad. Madrid: Ediciones Paulinas.

Gebara, Ivone. 1994. El rostro nuevo de Dios: la reconstrucción de los significados trinitarios y la celebración de la vida. México, D.F.: Ediciones Dabar. 
Gebara, Ivone. 2002. El rostro oculto del mal: una teología desde la experiencia de las mujeres. Madrid: Trotta.

Gutiérrez, Gustavo. 1975. Teología de la liberación. Perspectivas. $7^{\text {a }}$ ed. Salamanca: Ediciones Sígueme.

Gutiérrez, Gustavo. 1977. Teología desde el reverso de la historia. Lima, Perú: CEP.

Hartley, Ruth E. 1959. "Sex-role Pressures and the Socialization of the Male Child". Psychological Reports 5(h):457-68.

Hartsock, Nancy. 1983. Money, Sex, and Power: Toward a Feminist Historical Materialism. New York: Longman.

Haskin, Byron. 1954. Cuando ruge la marabunta. Jungla de Sur América: Paramount Spain, S.L.

Hill, Michael. 1976. Sociología de la religión. Madrid: Ediciones Cristiandad.

Hinkelammert, Franz J. 1998. El grito del sujeto: del teatro-mundo del evangelio de Juan al perro-mundo de la globalización. San José, Costa Rica: DEI.

Hurtado Cruchaga, Luis Alberto Miguel. 1941. ¿Es Chile un país católico? Santiago de Chile: Editorial Los Andes.

Izquierdo Brichs, Ferran y Athina Kemou. 2009. "La Sociología del poder en el mundo árabe contemporáneo". Pp. 17-59 en Poder y regímenes en el mundo Árabe contemporáneo, editado por F. Izquierdo Brichs. Barcelona: Fundación CIDOB.

Johns, Cheryl Briges. 2009. “Pentecostales y la práctica de la liberación: Propuesta para una formación teológica subversiva”. Pp. 136-52 en Movimiento pentecostal y comunidades de base en América Latina. La recepción de conceptos teológicos de liberación a través de la teología pentecostal, editado por M. Bergunder. Heidelberg: Universidad de Heidelberg.

Lagarde, Marcela. 1997. Claves feministas para el poderio y la autonomia de la mujeres: Memoria. Managua, Nicaragua: Puntos de Encuentro.

Lagarde, Marcela. 2005. Los cautiverios de las mujeres: madresposas, monjas, putas, presas y locas. Mexico, D.F.: Universidad Nacional Autonoma de Mexico (UNAM).

Lagarde, Marcela. 2012. “Claves feministas para la despatriarcalización”. Pp. 17-38 en Mujeres en diálogo. Avanzando hacia la despatriarcalización, editado por Coordinadora de la Mujer. La Paz, Bolivia: Coordinadora de la Mujer. Recuperado 16 de agosto de.

Lalive D’Epinay, Christian. 1968. El refugio de las masas. Estudio sociológico del protestantismo chileno. Santiago de Chile: Editorial del Pacífico.

Loudis, Richard, Del Castillo, Anu Rajaraman, y Marco Castillo. 2006. "Annex 2: Guatemala Profile". Pp. 59-87 en Central America and Mexico gang as- 
sessment, editado por USAID. Washington, D.C.: USAID Bureau for Latin American and Caribbean Affairs.

Marx, Karl. 1980. El Capital. México D.F.: Fondo de Cultura Económica.

Marx, Karl. 2005. Crítica de la filosofía del derecho de Hegel. Buenos Aires: Ediciones del Signo.

Masferrer Kann, Elio. 2004. ¿Es del César o es de Dios? Un modelo antropológico del campo religioso. México, D.F.: UNAM.

Merino, Juan. 2001. "La maras en Guatemala". en Maras y pandillas en Centroamérica, vol. 1, editado por Eric, Ideso, Idies, y Iudop. Managua, Nicaragua: UCA Publicaciones.

Merton, Robert King. 1964. Teoría y estructura sociales. Mexico, D.F.: Fondo de Cultura Económica.

Michels, Robert. 2008. Los partidos políticos: Un estudio sociológico de las tendencias oligárquicas de la democracia moderna. $2^{\text {a }}$ ed. España: Amorrortu Editores.

Michels, Roberts. 1969. Los partidos políticos: un estudio sociológico de las tendencias oligárquicas de la democracia moderna. España: Amorrortu Editores.

Míguez Bonino, José. 1995. Rostros del protestantismo latinoamericano. Grand Rapids/Buenos Aires: Nueva Creación.

Moltmann, Jürgen y Karl-Josef Kuschel. 1996. “Die Pfingstbewegung als Herausforderung". Concilium 32(3):207-208.

Moser, Carolin, Ailsa Winton, y Annalise Moser. 2005. "Violence, Fear, and Insecurity among the Urban Poor in Latin America”. Pp. 125-78 en The urban poor in Latin America, editado por M. Fay. Washington, D.C.: World Bank.

Nietzsche, Friedrich Wilhelm. 2009. La voluntad de poder. $17^{\mathrm{a}}$ ed. Madrid: EDAF.

Oakley, Ann. 1972. Sex, Gender, and Society. San Francisco: Harper and Row.

ONUDD. 2007a. Crimen Y Desarrollo En Centroamérica. Atrapados En Una Encrucijada. New York; Ginebra: Oficina de las Naciones Unidadas sobre Drogas y Crimen (ONUDC); Oficina de las Naciones Unidas contra la Droga y el Delito (ONUDD).

ONUDD. 2007b. InformeMundial sobre las drogas. New York: Naciones Unidas.

PDH. 2004. Muertes violentas de niñez, adolescencia y jóvenes y propuesta para su prevención. Guatemala: Procuraduría de los Derechos Humanos de Guatemala (PDH).

Peacock, Susan C. y Adriana Beltrán. 2004. Poderes ocultos: grupos ilegales armados en la Guatemala post conflicto y las fue[r]zas detrás de ellos. Washington, D.C.: Oficina en Washington para Asuntos Latinoamericanos (WOLA). 
Peetz, Peter. 2004. “Zentralamerikas Jugendbanden. 'Maras' in Honduras, El Salvador und Guatemala”. Brennpunkt Lateinamerika 5:49-64.

Pixley, Jorge y Clodovis Boff. 1986. Opción por los pobres. 2a ed. Madrid: Ediciones Paulinas.

Poljuve. 2009. Violencia juvenil, maras y pandillas en Guatemala. Guatemala: POLJUVE/INTERPACE.

Ranum, Elin Cecile. 2006. "Pandillas juveniles transnacionales en Centroamérica, México y Estados Unidos. Diagnóstico Nacional Guatemala”. Recuperado 25 de febrero de 2013.

Rodgers, Dennis. 2003. "Youth gangs in colombia and Nicaragua - New forms of violence, new theoretical directions?" Pp. 111-41 en Breeding inequality - Reaping violence. Exploring linkages and causality in Colombia and beyond, vol. 18; Outlook on Development Series, editado por A. Rudqvist. Uppsala, Sweden: Collegium for Development Studies.

Rolim, Francisco Cartaxo. 1980. Religião e clases populares. Petrópolis: Vozes.

Rolim, Francisco Cartaxo. 1985. Pentecostais no Brasil, una interpretacao socioreligiosa. Petrópolis: Vozes.

Román-López Dollinger, Angel Eduardo. 2013. “Gewalt, Kriminalität und Jugendbanden in Guatemala". Pp. 11-73 en Maras: Jugendbanden, Gewalt und organisiertes Verbrechen in Zentralamerika, Schriftenreihe Bibliothek am Guisanplatz, editado por A. E. Román-López Dollinger y A. K. Weltert. Bern: Bibliothek am Guisanplatz.

Román-López Dollinger, Angel Eduardo. 2014a. Basisorientierte Pastoral für marginalisierte Jugendliche mit abweichendem Verhalten. Eine empirisch-qualitative Forschung über die urbane Strassenpastoral der guatemaltekischen Pfingstbewegung. Berlín: Winter-Industries.

Román-López Dollinger, Angel Eduardo. 2014b. “Comunidades pentecostales de base en Latinoamérica. Un desafío actual para la teología”. Fe y Pueblo 24-25(tercera época):183-94.

Román-López Dollinger, Angel Eduardo. 2015. “Masculinidades y feminismo. Una mezcla política necesaria”. Pp. 123-34 en Teologías contextuales. Género e interculturalidad, editado por Y. Rosas, J. C. Chávez Quispe, A. E. RománLópez Dollinger, L. C. Qezada Barreto, y S. Lassak. La Paz, Bolivia: ISEAT.

Román-López Dollinger, Angel Eduardo. 2017. “Masculinidades pentecostales: Comunidades pentecostales de base como posibilidad para construir masculinidades no violentas en Guatemala". San José, Costa Rica: En prensa.

Román-López Dollinger, Angel Eduardo y Anna Katharina Weltert. 2013. Maras: Jugendbanden, Gewalt und organisiertes Verbrechen in Zentralamerika. Bern: Bibliothek am Guisanplatz. 
Santacruz Giralt, María L. y José Miguel Cruz Alas. 2001. “Las maras en El Salvador". Pp. 15-87 en Maras y pandillas en Centroamérica, vol. 1, editado por Eric, Ideso, Idies, y Iudop. Managua, Nicaragua: UCA Publicaciones.

Savenije, Wim. 2007. “Las Pandillas Trasnacionales o 'Maras'. Violencia Urbana En Centroamérica”. Foro Internacional XLVII(3):637-659.

Schäfer, Heinrich. 1992. Protestantismo y crisis social en América Central. San José, Costa Rica: DEI.

Schäfer, Heinrich. 2009. "La generación de sentido religioso. Observaciones acerca de la diversidad pentecostal en América Latina". Pp. 45-72 en Voces del pentecostalismo latinoamericano, vol. III: Teología, Historia, Identidad, editado por D. Chiquete y L. Orellana. Concepción de Chile: EMW/CETELA.

Schipani, Daniel. 1997. "Bases eclesiológicas: La iglesia como comunidad sanadora”. Pp. 3-25 en Psicología y Consejo Pastoral. Perspectiva Hispana, editado por D. Schipani y P. Jiménez. Decatur, Georia: Libros AETH.

Schüssler Fiorenza, Elisabeth. 2004. Los caminos de la Sabiduría: una introducción a la interpretación feminista de la Biblia. Santander: Sal Terrae.

Schüssler Fiorenza, Elisabeth. 2008. "Reclamando la autoridad de la interpretación bíblica”. Alternativas 15(36):15-32.

Schüssler Fiorenza, Elisabeth. 2011. Discipulado de iguales. Una Ekklesia-logía crítica feminista de liberación. La Paz, Bolivia: Pachamama.

Sepúlveda, Juan. 1992. "El crecimiento del movimiento pentecostal en América Latina". Pp. 77-88 en Pentecostalismo y liberación. Una experiencia latinoamericana, editado por C. Álvarez. San José, Costa Rica: Departamento Ecuménico de Investigaciones (DEI).

Sepúlveda, Juan. 2009. “Movimiento pentecostal y Teología de la Liberación. Dos manifiestaciones de la Obra del Espíritu Santo para la renovación de la Iglesia". Pp. 104-17 en Movimiento pentecostal y comunidades de base en América Latina. La recepción de conceptos teológicos de liberación a través de la teología pentecostal, editado por M. Bergunder. Heidelberg: Universität Heidelberg.

Smith, Dennis. 2006. Los teleapóstoles guatemaltecos y los medios electrónicos. Apuntes históricos y propuestas para la investigación. São Pablo: Congreso Latinoamericano sobre Religão e Etnicidade. Recuperado 25 de febrero de 2013.

Smutt, Marcela y Jenny Lissette Miranda. 1998. El fenómeno de las pandillas en El Salvador. San Salvador, El Salvador: UNICEF, FLACSO (Programa El Salvador).

Spergel, Irving A. 1995. The Youth Gang Problem: A Community Approach. New York: Oxford University Press. 
Spergel, Irving A. 2002. "Pandillas juveniles: Una crítica de estudios recientes". Delito y sociedad: revista de ciencias sociales (17):55-72.

Stoll, David. 1993. ¿América Latina se vuelve protestante? Quito, Ecuador: Ediciones Abya-Yala.

Stoller, Robert J. 1968. Sex and Gender: On the Development of Masculinity and Femininity. London: Hogarth Press.

Ullán de la Rosa, Francisco Javier. 2003. "Análisis del crecimiento pentecostal entre las clases populares e indígenas de Latinoamérica. Aplicación del modelo a una comunidad ticuna de la Alta Amazonía". Relaciones XXIV:227-265.

USAID, ed. 2006. Central America and Mexico Gang Assessment. Washington, D.C.: USAID Bureau for Latin American and Caribbean Affairs.

Valcárcel, Amelia. 1994. Sexo y filosofía: sobre "mujer" y "poder". Barcelona: Anthropos Editorial.

Valcárcel, Amelia. 1997. La política de las mujeres. Valencia, España: Universitat de València.

Vergara, Ignacio. 1962. El protestantismo en Chile. Santiago de Chile: Editorial del Pacífico.

Weber, Max. 1964. "El nacimiento de las religiones". Pp. 328-45 en Economía y sociedad. Esbozo de sociología comprensiva, editado por M. Weber. México, D.F.: Fondo de Cultura Económica..

Weber, Max. 1999. "Sociología de la religión". Recuperado 10 de septiembre de 2014.

Willems, Emilio. 1967. "El protestantismo y los cambios culturales en Brasil y Chile". Pp. 165-97 en Religión, revolución y reforma. Nuevas formas de transformación en Latinoamérica, editado por W. V. D’Antonio y F. B. Pike. Barcelona: Herder.

Zinecker, Heidrun. 2006. Gewalt im Frieden. Formen und Ursachen der Nachkriegsgewalt in Guatemala. Frankfurt am Main: Hessische Stiftung Friedensund Konfliktforschung (HSFK). 